\title{
Scenario analysis on abating industrial process greenhouse gas emissions from adipic acid production in China
}

\author{
Qing Tong ${ }^{1} \cdot$ Han-Yi Lin ${ }^{2} \cdot$ Xu-Ying Qin ${ }^{1} \cdot$ Run-Sheng Yan ${ }^{3} \cdot$ Yue-Feng Guo ${ }^{4} \cdot$ Xin-Yang Wei $^{5}$
}

Received: 19 November 2019/ Published online: 19 April 2020

(c) The Author(s) 2020

\begin{abstract}
Adipic acid is an important petrochemical product, and its production process emits a high concentration of greenhouse gas $\mathrm{N}_{2} \mathrm{O}$. This paper aims to provide quantitative references for relevant authorities to formulate greenhouse gas control roadmaps. The forecasting method of this paper is consistent with the published national inventory in terms of caliber. Based on the $\mathrm{N}_{2} \mathrm{O}$ abatement technical parameters of adipic acid and the production trend, this paper combines the scenario analysis and provides a measurement of comprehensive $\mathrm{N}_{2} \mathrm{O}$ abatement effect of the entire industry in China. Four future scenarios are assumed. The baseline scenario (BAUS) is a frozen scenario. Three emission abatement scenarios (ANAS, SNAS, and ENAS) are assumed under different strength of abatement driving parameters. The results show that China's adipic acid production process can achieve increasingly significant $\mathrm{N}_{2} \mathrm{O}$ emission abatement effects. Compared to the baseline scenario, by 2030, the $\mathrm{N}_{2} \mathrm{O}$ emission abatements of the three emission abatement scenarios can reach 207-399 kt and the emission abatement ratios can reach $32.5 \%-62.6 \%$. By 2050 , the $\mathrm{N}_{2} \mathrm{O}$ emission abatements for the three emission abatement scenarios can reach $387-540 \mathrm{kt}$ and the emission abatement ratios can reach $71.4 \%-99.6 \%$.
\end{abstract}

Keywords Scenario analysis $\cdot$ Industrial process greenhouse gas emissions $\cdot$ Adipic acid $\cdot \mathrm{N}_{2} \mathrm{O}$ emission abatement $\cdot$ China

\section{Introduction}

Industrial production process emissions refer to greenhouse gas emissions generated by chemical reactions and physical changes in industrial production (IPCC 1996). These emissions do not include energy activities. The petroleum and chemical industries are the main sources of greenhouse gas

Edited by Xiu-Qiu Peng

Xin-Yang Wei

xywei@must.edu.mo

1 Institute of Nuclear and New Energy Technology, Tsinghua University, Beijing 100084, China

2 School of Energy, Power and Mechanical Engineering, North China Electric Power University, Beijing 102206, China

3 Environmental Protection Research Institute of Light Industry, Beijing 100089, China

4 State Key Laboratory of Virtual Reality and Suzhou Institute of Beihang University, Suzhou 215200, China

5 Department of Accounting and Finance, School of Business, Macau University of Science and Technology, Macau 999078, China emissions from industrial processes in China due to a large number of chemical reactions involved. In 2014, greenhouse gas emissions from China's petroleum and chemical production process reached 238 million $\mathrm{tCO}_{2}$ equivalent (NDRC China 2018), which accounted for about $14 \%$ of the total industrial production process emissions. Adipic acid is an important petrochemical product, and its production process includes a greenhouse gas emission source, namely $\mathrm{N}_{2} \mathrm{O}$ emissions. $\mathrm{N}_{2} \mathrm{O}$ is a by-product of the adipic acid production process, and it is mainly derived from the oxidant nitric acid in its production (IPCC 2006).

The commercialized production of adipic acid in China mainly adopts the cyclohexane method. This method mainly comprises two steps (Shimizu et al. 2000; Frutos et al. 2018): The first step is to conduct catalytic hydrogenation of pure benzene in order to obtain cyclohexane, and then, cyclohexane is further oxidized to obtain a mixture of cyclohexanol-cyclohexanone (Alcohol ketone, also known as KA oil). This step does not involve greenhouse gas emissions. The second step is the oxidation of KA oil, which utilizes nitric acid to oxidize KA oil and then produces adipic acid after crystallization and drying. This step will generate nitrous oxide $\left(\mathrm{N}_{2} \mathrm{O}\right)$ emissions. 
The Chinese government released China's greenhouse gas inventories in 2005 (NDRC China 2014; NDRC China 2016), 2010 (NDRC China 2018), 2012 (NDRC China 2016), and 2014 (NDRC China 2018). The four years' greenhouse gas inventories are consistent in the accounting methods and data caliber of adipic acid production processes. They combined the methodologies of the Good Practice Guidance and Uncertainty Management in National Greenhouse Gas Inventories (GPG2000) (IPCC 2000) and the 2006 IPCC Guidelines for National Greenhouse Gas Inventories (2006 IPCC GLs) (IPCC 2006) with China's actual situation. The level of activities (adipic acid production), $\mathrm{N}_{2} \mathrm{O}$ emissions, and the sectoral average emission factors (implied emission factors) are shown in Table 1.

The data show that both the adipic acid production and $\mathrm{N}_{2} \mathrm{O}$ emissions from China's adipic acid industry continued to increase during 2005-2014. However, the year 2012 was a critical point that the variation trends of adipic acid production and $\mathrm{N}_{2} \mathrm{O}$ emissions diverged. In 2005-2012, the average annual growth rate of adipic acid production was $20.3 \%$ and the average annual growth rate of $\mathrm{N}_{2} \mathrm{O}$ emissions was $15.6 \%$. During this period, the growth rate of $\mathrm{N}_{2} \mathrm{O}$ emissions from the adipic acid production process was significantly lower than the growth rate of adipic acid production. The main reason is that in 2010-2012, based on the cooperation of the international Clean Development Mechanism project, the adipic acid industry conducted a series of $\mathrm{N}_{2} \mathrm{O}$ emission abatement activities (Tong 2011; Lee et al. 2011; Yan et al. 2018; Lu 2009) so that the implied emission factors decreased. However, due to the suspension of international cooperation in 2013 (Tong et al. 2012), domestic companies were unable to withstand high abatement costs (Tong et al. 2012; Frutos et al. 2018), and the implied emission factor in 2014 rebounded to beyond 2005 level. Therefore, in 2012-2014, although the average annual growth rate of adipic acid production was only $0.6 \%$, the average annual growth rate of $\mathrm{N}_{2} \mathrm{O}$ emissions was as high as $16.9 \%$. The historical variation trends of adipic acid production and $\mathrm{N}_{2} \mathrm{O}$ emissions reflect the important role of emission abatement measures on the production side in controlling greenhouse emissions from adipic acid industry.

Only a few countries in the world, such as the USA, the European Union member states, Japan, and China, are able to produce adipic acid. Due to the confidentiality needs by the small number of enterprises, statistics of adipic acid

Table 1 Historical $\mathrm{N}_{2} \mathrm{O}$ emissions from China's adipic acid industry

\begin{tabular}{lcccc}
\hline Year & 2005 & 2010 & 2012 & 2014 \\
\hline Adipic acid production, kt & 203.17 & 666.70 & 740.32 & 749.00 \\
Implied emission factor, $\mathrm{tN}_{2} \mathrm{O} / \mathrm{t}$ & 0.293 & 0.206 & 0.222 & 0.3 \\
Total $\mathrm{N}_{2} \mathrm{O}$ emissions, kt & 59.53 & 137.34 & 164.35 & 224.70 \\
\hline
\end{tabular}

production are rarely published in these countries. At present, the research on $\mathrm{N}_{2} \mathrm{O}$ emissions and abatements in the production process of adipic acid is very limited in China as well as other countries. The focus of the existing literature is laid on emission inventories and emission abatement technology review, and there is no published literature forecasting $\mathrm{N}_{2} \mathrm{O}$ emission from the adipic acid production process. Furthermore, within the current literature on emission inventories and emission abatement technology, the following limitations exist:

(1) Emissions inventories Due to data confidentiality reasons, the foreign emission inventories rarely disclose the sectoral average emission factors (implied emission factors) of the adipic acid production process (US EPA 2019; German FEA 2019; Japan MOE 2019; France CITEPA 2019; Canada ECC 2019). Therefore, the penetration rates as well as the effect of emission abatements by abatement technologies cannot be reflected in national inventories, and the research results are lack of transparency.

(2) Abatement technologies Some source control technologies only stay in the stage of laboratory research (Kang 1999; Zhang 2002; Hao et al. 2012; Shi 2015), and therefore, it will be difficult to implement these technologies before 2050 taking into account the situation of overcapacity in China's adipic acid industry. There are also some end treatment technologies described in the literature, and they focus on the design of process routes (Cao et al. 2018; Yan et al. 2018; Zhu 2013; Jiang et al. 2018), or case studies (Yu 2016; Zhang 2009; Zhao 2008), which do not present the quantitative results for $\mathrm{N}_{2} \mathrm{O}$ abatements for the entire adipic acid industry.

Although the adipic acid industry has a small number of companies, it emits a high concentration of $\mathrm{N}_{2} \mathrm{O}$ exhaust gas. $\mathrm{N}_{2} \mathrm{O}$ is a type of greenhouse gas with a high global warming potential, and one ton of $\mathrm{N}_{2} \mathrm{O}$ emissions is equivalent to 310 tons of $\mathrm{CO}_{2}$ equivalent (IPCC 1995). China now is one of the world's major producers of adipic acid. Therefore, it is not only necessary to prepare the emission inventory and understand the emission status, but also to predict the emission abatement potential of the adipic acid production process. The forecasting method of this paper is consistent with the published national inventory in terms of caliber. Starting from the emission abatement technical parameters of adipic acid (the production side) and the production trend (the demand side), this paper combines the scenario analysis method and provides the measurement of comprehensive emission abatement effect of the whole industry in China. It presents the $\mathrm{N}_{2} \mathrm{O}$ emission forecast and abatement path analysis of China's adipic acid production process by 2050 . 
It can fill in the corresponding research gaps in China and provide quantitative references for the relevant authorities to formulate relevant roadmaps.

The remainder of this paper is organized as follows. Section 2 describes research methodologies and scenario assumptions based on $\mathrm{N}_{2} \mathrm{O}$ abatement technology penetration and adipic acid production forecast. Section 3 discusses the results, including implied emission factors, activity data, and $\mathrm{N}_{2} \mathrm{O}$ emissions from adipic acid production. Section 4 draws conclusions which could provide relevant implications for related administrative departments and policymakers.

\section{Methodology and scenario assumptions}

\subsection{Methodology}

\subsubsection{Forecasting $\mathrm{N}_{2} \mathrm{O}$ emissions}

The prediction method is consistent with the published national inventories, which can forecast the nitrous oxide emissions from adipic acid production using the so-called "Emission Factor Method" (IPCC 2006), as shown in formula (1). Based on the latest available data for 2014, the activity data (adipic acid production) and emission factors for the target year are predicted separately, and the multiplication of the two parameters is the nitrous oxide emissions from the adipic acid production process in the target year.

$E_{\mathrm{N}_{2} \mathrm{O}}=\mathrm{EF} \times \mathrm{AD}$

where $E_{\mathrm{N}_{2} \mathrm{O}}$ is the nitrous oxide emission $\left(\mathrm{ktN}_{2} \mathrm{O}\right)$ from the adipic acid production process in the target year; $\mathrm{EF}$ is the nitrous oxide emission factor $\left(\mathrm{tN}_{2} \mathrm{O} / \mathrm{t}\right)$ from the adipic acid production process; and $\mathrm{AD}$ is the annual adipic acid production $(\mathrm{kt})$ in the target year.

\subsubsection{Emission factor forecasting}

The emission factors analyzed in this paper are sectoral implied emission factors that take into account the effects of greenhouse gas emission abatement technologies implemented from the production side (Tong et al. 2019).

The greenhouse gas abatement technologies for adipic acid production process include the following two categories:

(1) Source control technologies

The adipic acid industry in China now mainly adopts cyclohexane production technology. The adipic acid production capacity from the cyclohexane method accounts for more than $95 \%$ of the total adipic acid production capacity in China (Zhu 2013). Therefore, the $\mathrm{N}_{2} \mathrm{O}$ source control technology of the adipic acid industry mainly uses other raw material routes or methods to replace the adipic acid production capacity of the cyclohexane method (Zhao 2008; Hao et al. 2012). The cyclohexanol method was first used by Asahi Kasei Corporation of Japan. Although the raw material is similar to the cyclohexane method, the consumption of hydrogen and nitric acid is significantly reduced. Therefore, the $\mathrm{N}_{2} \mathrm{O}$ emission abatement effect is obtained. In addition, the literature also reports the adipic acid production method which can completely remove $\mathrm{N}_{2} \mathrm{O}$ emissions. With $30 \%$ hydrogen peroxide in the action of sodium tungstate and catalyst, this method directly oxidizes cyclohexene into adipic acid with a $90 \%$ production rate (Kang 1999; Hao et al. 2012). However, this method is only attractive when the price of hydrogen peroxide is not high and in a policy environment where the $\mathrm{N}_{2} \mathrm{O}$ emissions are strictly controlled. Also, the industrialization of this method has not been achieved yet. Moreover, butadiene method, ozone plus ultraviolet radiation, and other methods have no $\mathrm{N}_{2} \mathrm{O}$ emissions due to the lack of nitric acid oxidation (Hao et al. 2012; Shi 2015). These methods are currently in the stage of laboratory research. As to the adipic acid industry where overcapacity has emerged, whether these technologies can be commercialized by 2050 is highly uncertain and not enforceable.

(2) End treatment technology

One of the end treatment technologies for adipic acid industry involves catalytic decomposition, and its $\mathrm{N}_{2} \mathrm{O}$ abatement mechanism is similar to the end treatment technology of the nitric acid industry. However, due to the disadvantages of high cost and short lifespan of catalyst, the thermal decomposition method is more widely used than the catalytic decomposition method as the end treatment technology in adipic acid industry. The thermal decomposition method directly sends the $\mathrm{N}_{2} \mathrm{O}$ exhaust into the incinerator and decomposes $\mathrm{N}_{2} \mathrm{O}$ to $\mathrm{N}_{2}, \mathrm{O}_{2}$, and $\mathrm{NO}$ at high temperature with no catalyst. It can also achieve a part of nitric acid recycling and waste heat utilization. However, the disadvantage is that fuel is consumed, which generates additional carbon dioxide emissions. The theoretical abatement efficiency of catalytic decomposition and thermal decomposition technology can reach 98\% (IPCC 2006; Lee et al. 2011; Yan et al. 2018; Lu 2009).

In addition, the literature proposes methods for the direct purification and recycling of $\mathrm{N}_{2} \mathrm{O}$ generated from the chemical production process, which can further produce phenol and medical laughing gas anesthetics, etc. (Jiang et al. 2018; Yan et al. 2018). These methods are significantly associated with the prices of downstream 
products from the demand side, and they have not been commercialized yet.

Therefore, the scenario analysis in this paper only incorporates the parameters of commercialized end treatment technologies into the deduction of emission factors taking into account the overcapacity situation of China's adipic acid industry and abatement technology availability.

For the forecasting of emission factors, this paper considers the application and corresponding influence of the end treatment technology in the adipic acid production industry in China, and the end treatment technology is mainly based on thermal decomposition technology. The nitrous oxide emission factor of the adipic acid production process can be quantitatively predicted using formula (2).

$\mathrm{EF}=\mathrm{EF}_{0} \times\left(1-T_{\mathrm{R}} \times R\right)$

where $\mathrm{EF}$ is the nitrous oxide emission factor $\left(\mathrm{tN}_{2} \mathrm{O} / \mathrm{t}\right)$ of the adipic acid production process in the target year; $\mathrm{EF}_{0}$ is the nitrous oxide emission factor $\left(\mathrm{tN}_{2} \mathrm{O} / \mathrm{t}\right)$ of the adipic acid production process in the base year (2014); $\mathrm{T}_{R}$ is the penetration rate of the $\mathrm{N}_{2} \mathrm{O}$ decomposition technology in the target year; and $R$ is the decomposition efficiency of the $\mathrm{N}_{2} \mathrm{O}$ decomposition technology in the target year.

\subsubsection{Activity data Forecasting}

According to the 2006 IPCC GLs, the activity data are adipic acid production.

According to the China Industrialization Process Report released by the Chinese Academy of Social Sciences, China has entered the late stage of industrialization and will basically achieve industrialization by 2020 (Wen 2017). Referring to the trends of major developed countries' chemical industry, the productions will peak before the end period of industrialization. China's chemical industry is currently facing problems such as overcapacity and operating below the productive capacity. Therefore, in this paper, the total adipic acid production is assumed to peak in 2020. The major developed countries such as the USA, Japan, and the European Union have a longer history of adipic acid production than China, and these countries have accumulated 28 years of emissions inventory data. According to the inventory data of these countries, most of their adipic acid production peaked in the last century, and then, the data presented a downward trend with different rates. The rate of change in adipic acid production in developed countries can provide a quantitative reference for China's forecasting work.

According to the industry's "13th Five-Year Plan" and other policy objectives, this study forecasts peak production in 2020. By referring to the decline in production in major developed countries such as the USA, Japan, and the European Union, this paper sets the annual average rate of adipic acid production decline (five-year cycles) for the period of 2020 to 2050 . This study uses formula (3) to calculate the output of each target year from 2025 to 2050 .

$A D_{\mathrm{t}}=A D_{\mathrm{b}} \times(1-d)^{5}$

where $A D_{\mathrm{t}}$ is the annual adipic acid production (kt) in the target year; $A D_{b}$ is the adipic acid production (kt) in the base year for a five-year period; and $d$ is the annual average rate of decline in adipic acid production.

\subsection{Scenario assumptions}

Four scenarios are assumed for forecasting analysis.

\subsubsection{Business as usual scenario (BAUS)}

The baseline scenario (BAUS) is a frozen scenario, and it does not consider any technological progress (Yang et al. 2016). Since $\mathrm{N}_{2} \mathrm{O}$ is not a conventional pollutant, there is no mandatory $\mathrm{N}_{2} \mathrm{O}$ emission abatement requirement in China, and it is reasonable to set up a technical freeze. The emission factor for each target year is consistent with the base year, which is $0.3 \mathrm{tN}_{2} \mathrm{O} / \mathrm{t}$. The adipic acid production for 2020 is expected to be $2300 \mathrm{kt}$ (Jinzhi Innovation Company 2019). The annual average rate of decline in production for each target year thereafter is set to $0.8 \%$ with reference to the British trend (UK BEIS 2019).

\subsubsection{Appropriate $\mathrm{N}_{2} \mathrm{O}$ abatement scenario (ANAS)}

On June 30, 2015, the Chinese government submitted "Strengthening Actions to Address Climate Change-China's National Independence Contribution" to the United Nations (NDRC China 2015). The document proposed "actively controlling greenhouse gas emissions from industrial production processes" but did not specify quantitative control objectives.

Based on the above policy documents, the ANAS scenario quantifies the control objectives (or drive parameters) for both the production side and the demand side of adipic acid production, including.

For the production side, this scenario assumes that there will be policy guidance to promote the use of end treatment technology in adipic acid industry. The technology penetration rate is set at $9 \%$ in 2020 . This means the end treatment devices of China's adipic acid producers that were shut down in 2013 could be put back into operation in 2020 . The technology penetration rate will increase to $60 \%$ in 2050 (Zhu et al. 2017). Correspondingly, the efficiency of technology decomposition will gradually increase from $88 \%$ in 2020 to $98 \%$. The scenario uses interpolation to estimate emission factor-related parameters for the intermediate target years. 
For the demand side, this scenario assumes that there will be policy guidance to moderately reduce the demand for adipic acid in downstream industries, thus achieving the adipic acid production control. The adipic acid production is expected to be $2300 \mathrm{kt}$ by 2020 (Jinzhi Innovation Company 2019). The annual average rate of decline in production for each target year thereafter is based on the German trend (German FEA 2019), which is set at $2 \%$.

The driving parameters of abatement approaches in this scenario are shown in Table 2.

\subsubsection{Strengthened $\mathrm{N}_{2} \mathrm{O}$ abatement scenario (SNAS)}

The strengthened $\mathrm{N}_{2} \mathrm{O}$ abatement scenario (SNAS) considers the same path to reduce $\mathrm{N}_{2} \mathrm{O}$ emissions from adipic acid production process as the appropriate $\mathrm{N}_{2} \mathrm{O}$ abatement scenario (ANAS), but it is with greater abatement strength as follows:

For the production side, this scenario assumes that there will be policy guidance to promote the use of end treatment technology in adipic acid industry. The technology penetration rate is set at $9 \%$ in 2020 . This means the end treatment devices of China's adipic acid producers that were shut down in 2013 could be put back into operation in 2020 . The technology penetration rate will increase to $80 \%$ in 2050 . Correspondingly, the efficiency of technology decomposition will gradually increase from $88 \%$ in 2020 to $98 \%$. The scenario uses interpolation to estimate emission factor-related parameters for the intermediate target years.

For the demand side, on the basis of the ANAS scenario, this scenario assumes that there will be policy guidance to further reduce the demand for adipic acid in downstream industries to achieve adipic acid production control. The adipic acid production is expected to be $2300 \mathrm{kt}$ by 2020 (Jinzhi Innovation Company 2019). The annual average rate of decline in production for each target year thereafter is set at 3\% with reference to the US trend (US EPA 2019).
The driving parameters of abatement approaches in this scenario are shown in Table 3.

\subsubsection{Extreme $\mathrm{N}_{2} \mathrm{O}$ Abatement Scenario (ENAS)}

The extreme $\mathrm{N}_{2} \mathrm{O}$ abatement scenario (ENAS) considers the same path to reduce emissions as the SNAS and ANAS, but it is with the largest abatement strength. In terms of $\mathrm{N}_{2} \mathrm{O}$ emission abatement technology, it is specifically assumed that by 2050 , the maximum emission abatement effect will be achieved, which cannot be broken through. The specific scenarios are as follows:

For the production side, this scenario assumes that there will be policy guidance to greatly promote the use of end treatment technology in adipic acid industry. The technology penetration rate is set at $9 \%$ in 2020 . This means the end treatment devices of China's adipic acid producers that were shut down in 2013 could be put back into operation in 2020. The technology penetration rate will increase to $100 \%$ in 2050 . Correspondingly, the efficiency of technology decomposition will gradually increase from $88 \%$ in 2020 to $98 \%$. The scenario uses interpolation to estimate emission factor-related parameters for the intermediate target years.

For the demand side, this scenario assumes that there will be policy guidance to significantly reduce the demand for adipic acid in downstream industries, thus achieving strict control of adipic acid production. The adipic acid production is expected to be $2300 \mathrm{kt}$ by 2020 (Jinzhi Innovation Company 2019). The annual average rate of decline in production for each target year thereafter is set at $6 \%$ with reference to the French trend (France CITEPA 2019).

The driving parameters of abatement approaches in this scenario are shown in Table 4.

Table 2 Driving parameters of abatement approaches under the ANAS

\begin{tabular}{|c|c|c|c|c|c|}
\hline Classification & Driving parameters & $2020, \%$ & $2030, \%$ & $2040, \%$ & $2050, \%$ \\
\hline \multirow[t]{2}{*}{ Production-based } & End treatment technology penetration rate & 9 & 26 & 43 & 60 \\
\hline & End treatment technology efficiency & 88 & 91.33 & 94.67 & 98 \\
\hline Demand-based & The annual change rate of adipic acid production & -2 & -2 & -2 & -2 \\
\hline
\end{tabular}

Table 3 Driving parameters of abatement approaches under the SNAS

\begin{tabular}{|c|c|c|c|c|c|}
\hline Classification & Driving parameters & $2020, \%$ & $2030, \%$ & $2040, \%$ & $2050, \%$ \\
\hline \multirow[t]{2}{*}{ Production-based } & End treatment technology penetration rate & 9 & 32.67 & 56.33 & 80 \\
\hline & End treatment technology efficiency & 88 & 91.33 & 94.67 & 98 \\
\hline Demand-based & The annual change rate of adipic acid production & -3 & -3 & -3 & -3 \\
\hline
\end{tabular}


Table 4 Driving parameters of abatement approaches under the ENAS

\begin{tabular}{|c|c|c|c|c|c|}
\hline Classification & Driving parameters & $2020, \%$ & $2030, \%$ & $2040, \%$ & $2050, \%$ \\
\hline \multirow[t]{2}{*}{ Production-based } & End treatment technology penetration rate & 9 & 39.33 & 69.67 & 100 \\
\hline & End treatment technology efficiency & 88 & 91.33 & 94.67 & 98 \\
\hline Demand-based & The annual change rate of adipic acid production & -6 & -6 & -6 & -6 \\
\hline
\end{tabular}

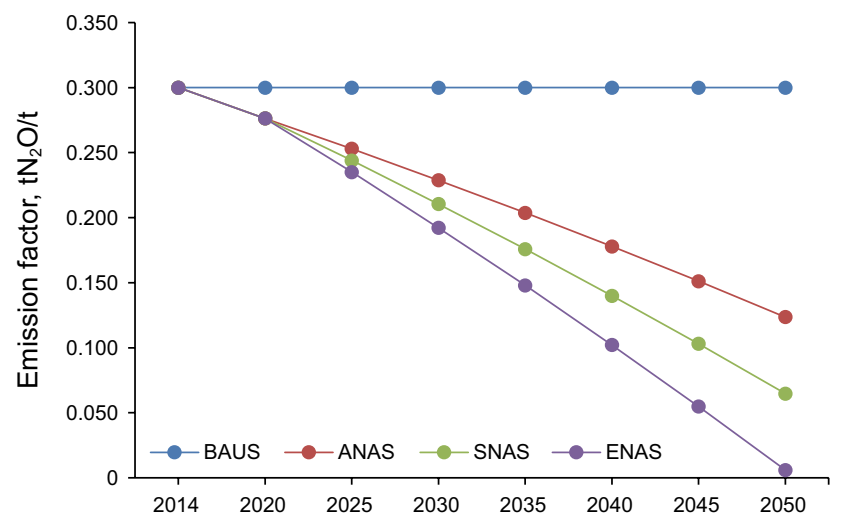

Fig. 1 Emission factors for each scenario $\left(\mathrm{tN}_{2} \mathrm{O} / \mathrm{t}\right)$

\section{Analysis of results}

\subsection{Emission factors}

The baseline scenario BAUS is technically frozen, so the emission factors for all target years are the same as for the base year, which is $0.3 \mathrm{tN}_{2} \mathrm{O} / \mathrm{t}$ adipic acid. The emission factors of the other three emission abatement scenarios show decreasing trends in 2020-2050, in which the rate of declining is accelerated in the order of ANAS, SNAS, and ENAS. By 2030, the emission factors for the three emission abatement scenarios are $0.229 \mathrm{tN} 2 \mathrm{O} / \mathrm{t}$ adipic acid, $0.210 \mathrm{tN}_{2} \mathrm{O} / \mathrm{t}$ adipic acid, and $0.192 \mathrm{tN}_{2} \mathrm{O} / \mathrm{t}$ adipic acid. Compared to the baseline scenario BAUS, the emission factors are reduced by $23.7 \%, 30 \%$, and $36 \%$, respectively. By 2050 , the emission factors for the three emission abatement scenarios are $0.124 \mathrm{tN}_{2} \mathrm{O} / \mathrm{t}$ adipic acid, $0.065 \mathrm{tN}_{2} \mathrm{O} / \mathrm{t}$ adipic acid, and $0.006 \mathrm{tN}_{2} \mathrm{O} / \mathrm{t}$ adipic acid, and the emission factors are reduced by $58.7 \%, 78.3 \%$, and $98 \%$, respectively, compared to the baseline scenario. The results are shown in Fig. 1.

\subsection{Activity data}

The adipic acid outputs in all four scenarios reach a peak of $2300 \mathrm{kt}$ in 2020 . The adipic acid outputs in the baseline scenario BAUS show a slow downward trend after

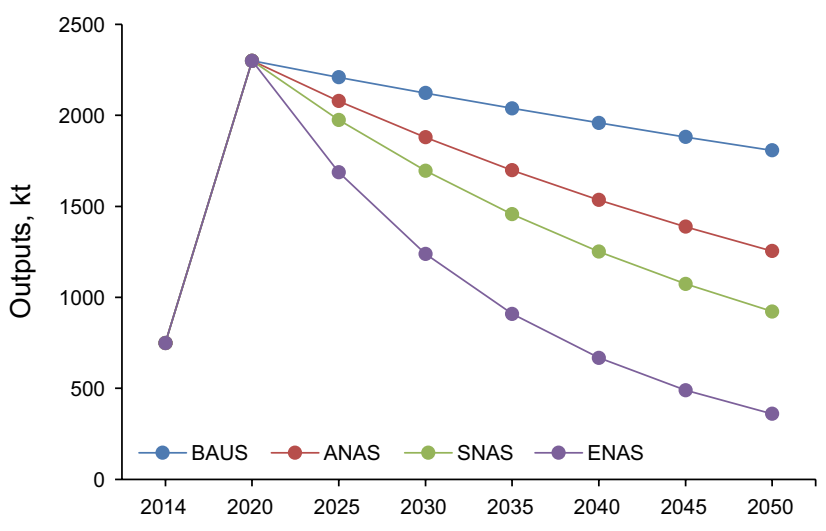

Fig. 2 Adipic acid outputs in each scenario

reaching the peak. The adipic acid output for this scenario falls to $2123 \mathrm{kt}$ in 2030 and further falls to $1807 \mathrm{kt}$ in 2050. The outputs of the three emission abatement scenarios show more obvious decreasing trends in 2020-2050. By 2030, the adipic acid outputs for the three emission abatement scenarios are $1879 \mathrm{kt}, 1696 \mathrm{kt}$, and $1238 \mathrm{kt}$, respectively, while their decrease ratios are $11.5 \%, 20.1 \%$, and $41.7 \%$ compared to the baseline scenario (BAUS). By 2050 , the adipic acid outputs of the three emission abatement scenarios are $1255 \mathrm{kt}, 922 \mathrm{kt}$, and $359 \mathrm{kt}$, respectively, while their decrease ratios are $30.6 \%, 49.0 \%$, and $80.1 \%$ compared to the baseline scenario. See Fig. 2 for details.

\section{3 $\mathrm{N}_{2} \mathrm{O}$ emissions from adipic acid production process}

$\mathrm{N}_{2} \mathrm{O}$ emissions from the adipic acid production process in the four scenarios will all peak in 2020. The baseline scenario has a peak $\mathrm{N}_{2} \mathrm{O}$ emissions of $690 \mathrm{kt}$, followed by a slow downward trend with $637 \mathrm{kt}$ in 2030 and $542 \mathrm{kt}$ in 2050. Although the peak of adipic acid production in the three emission abatement scenarios is the same as the baseline scenario, their peak of $\mathrm{N}_{2} \mathrm{O}$ emissions are lower than the baseline scenario's value due to the assumption of the application of emission abatement technologies. The $\mathrm{N}_{2} \mathrm{O}$ emissions of the three emission abatement scenarios show decreasing trends after peaking, in which the emission abatement paces are accelerated in the order of ANAS, SNAS, 
and ENAS. By 2030, the $\mathrm{N}_{2} \mathrm{O}$ emissions of the three emission abatement scenarios are $430 \mathrm{kt}, 357 \mathrm{kt}$, and $238 \mathrm{kt}$, respectively, while their decrease ratios are $32.5 \%, 44.0 \%$, and $62.6 \%$ compared to the baseline scenario. By 2050, the $\mathrm{N}_{2} \mathrm{O}$ emissions of the three emission abatement scenarios are $155 \mathrm{kt}, 60 \mathrm{kt}$, and $2 \mathrm{kt}$, respectively, while their decrease ratios are $71.4 \%, 88.9 \%$, and $99.6 \%$ compared to the baseline scenario. See Fig. 3 for details. Due to the integrated effects from both the production side and the demand side control, the decrease in $\mathrm{N}_{2} \mathrm{O}$ emissions from adipic acid production process is faster than the decrease in adipic acid outputs. In particular, the ENAS scenario will achieve near-zero emissions by 2050 .

\subsection{Effect of emission abatement}

Based on the emissions forecasting data of the BAU scenario, this section compares the emission abatement amounts and emission abatement ratios achieved in each target year of each emission abatement scenario in order to measure the emission abatement effects. The concept of emission abatement ratio is similar to the decrease ratio of $\mathrm{N}_{2} \mathrm{O}$ emissions compared to the baseline scenario which is described in Sect. 3.3.

Compared to the baseline scenario, by 2020 , the $\mathrm{N}_{2} \mathrm{O}$ emission abatements in the three emission abatement scenarios are $55 \mathrm{kt}$ and the reduction ratio is $8.0 \%$. After 2020, the emission abatement effects of the three emission abatement scenarios will increase in turn, which show differences. By 2030, the $\mathrm{N}_{2} \mathrm{O}$ emission abatements for the three emission abatement scenarios are $207 \mathrm{kt}, 280 \mathrm{kt}$, and $399 \mathrm{kt}$. The emission abatement ratios are $32.5 \%, 44.0 \%$, and $62.6 \%$. By 2050 , the $\mathrm{N}_{2} \mathrm{O}$ emission abatements for the three emission abatement scenarios are $387 \mathrm{kt}, 482 \mathrm{kt}$, and $540 \mathrm{kt}$. The emission abatement ratios are $71.4 \%, 88.9 \%$, and $99.6 \%$. The emission abatements for each scenario are shown in Fig. 4.

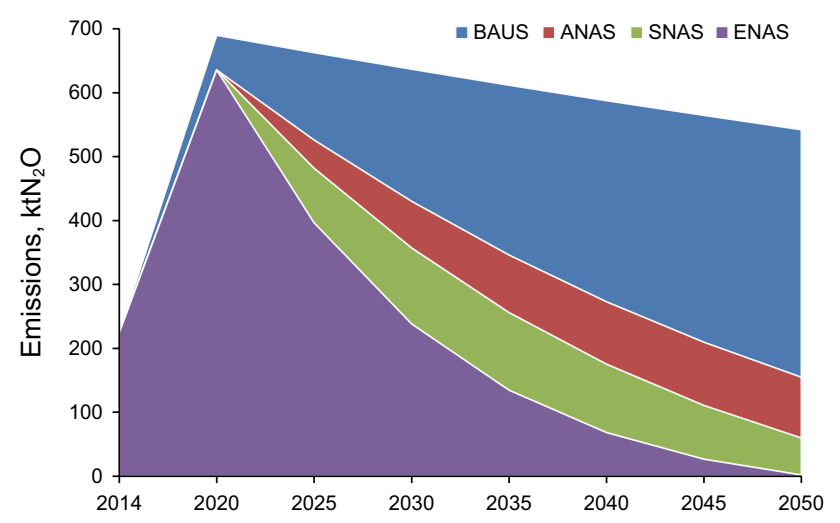

Fig. $3 \mathrm{~N}_{2} \mathrm{O}$ emissions from adipic acid production in each scenario



Fig. $4 \mathrm{~N}_{2} \mathrm{O}$ emission abatements in abatement scenarios compared to BAUS emission levels

The emission abatement rates for each scenario are shown in Fig. 5.

\section{Conclusion}

The results of this paper indicate that the abatement of $\mathrm{N}_{2} \mathrm{O}$ emissions from the adipic acid production process can be achieved bidirectionally from the production side and the demand side. The main emission abatement approach from the adipic acid production side is to promote the use of end treatment technologies. The demand side of the emission abatement path is to reduce the demand for adipic acid in downstream industries, thereby controlling adipic acid outputs.

In terms of production side emission abatements, the end treatment control technology penetration rates of the three emission abatement scenarios set in this paper increase in turn, reaching $26 \%-39 \%$ in 2030 and $60 \%-100 \%$ in 2050. Based on this, the forecasted decrease rates of

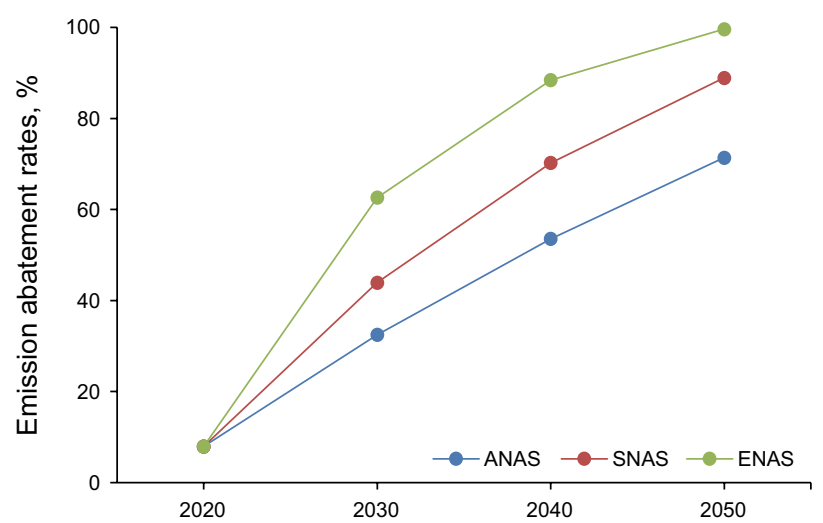

Fig. $5 \mathrm{~N}_{2} \mathrm{O}$ emission abatement rates in abatement scenarios compared to BAUS emission levels 
sectoral average emission factors reach $24 \%-36 \%$ in 2030 and $59 \%-98 \%$ in 2050 compared to the baseline scenario.

In terms of demand side control, the current situation of overcapacity and operating below the productive capacity in adipic acid industry and its downstream industries has been fully considered in this paper. Combined with the literature research data, this study sets the same peaking value of adipic acid outputs in four scenarios in 2020, which is $2300 \mathrm{kt}$. Referring to the trend of adipic acid production in developed countries, it is predicted that the adipic acid production of the three abatement scenarios shows different decreasing trends after peaking, in which the decrease rates are accelerated in the order of ANAS, SNAS, and ENAS. Compared to the baseline scenario, by 2030, the adipic acid outputs of the three emission abatement scenarios will decrease $11.5 \%-41.7 \%$ and $30.6 \%-80.1 \%$ in 2050 .

Through the integration of the above two emission abatement approaches, China's adipic acid production process can achieve increasingly significant $\mathrm{N}_{2} \mathrm{O}$ emission abatement effects. Compared to the baseline scenario, by 2030, the $\mathrm{N}_{2} \mathrm{O}$ emission abatements of the three emission abatement scenarios can reach 207-399 kt and the emission abatement ratios can reach $32.5 \%-62.6 \%$. By 2050, the $\mathrm{N}_{2} \mathrm{O}$ emission abatements for the three emission abatement scenarios can reach $387-540 \mathrm{kt}$ and the emission abatement ratios can reach $71.4 \%-99.6 \%$.

From the results of this paper, the following policy implications could be provided for controlling $\mathrm{N}_{2} \mathrm{O}$ emissions from adipic acid industry in China: (1) From the production side, since there would be additional costs burdened to adipic acid producers to install and operate the end treatment equipments, there should be some market measures or subsidy policy to reduce the producers' $\mathrm{N}_{2} \mathrm{O}$ abatement costs. (2) From the demand side control, there should be some guidance to green production and green life-style to reduce the demand of adipic acid.

Acknowledgements The authors acknowledge the financial support by the Ministry of Science and Technology of China (Grant No. 2018YFC1509006), the National Natural Science Foundation of China (Grant No. 71874096), the Macau SAR Government Higher Education Fund, and the Macau University of Science and Technology (Grant No. FRG-19-008-MSB).

Open Access This article is licensed under a Creative Commons Attribution 4.0 International License, which permits use, sharing, adaptation, distribution and reproduction in any medium or format, as long as you give appropriate credit to the original author(s) and the source, provide a link to the Creative Commons licence, and indicate if changes were made. The images or other third party material in this article are included in the article's Creative Commons licence, unless indicated otherwise in a credit line to the material. If material is not included in the article's Creative Commons licence and your intended use is not permitted by statutory regulation or exceeds the permitted use, you will need to obtain permission directly from the copyright holder. To view a copy of this licence, visit http://creativecommons.org/licenses/by/4.0/.

\section{References}

Cao YL et al. Study on the application conditions of catalyst for $\mathrm{N}_{2} \mathrm{O}$ catalytic decomposition in industrial pilot scale. Environ Pollut Control. 2018;40(1):80-3 (In Chinese).

Environment and Climate Change Canada. National Inventory Report 1990-2017: Greenhouse gas sources and sinks in Canada. https:// www.canada.ca/en/environment-climate-change/services/climatechange/greenhouse-gas-emissions.html. Accessed 17 Nov 2019.

France CITEPA. Rapport National d'Inventaire pour la France. https:// www.citepa.org/wp-content/uploads/publications/ccnucc/CCNUC C_france_2019.pdf. Accessed on 17 Nov 2019.

Frutos OD, Quijano G, Aizpuru A, Munoz R. A state-of-the-art review on nitrous oxide control from waste treatment and industrial sources. Biotechnol Adv. 2018;2018(36):1025-37. https://doi. org/10.1016/j.biotechadv.2018.03.004.

German Federal Environment Agency. National Inventory Report for the German Greenhouse Gas Inventory. https://www.umwel tbundesamt.de/themen/klima-energie/treibhausgas-emissionen. Accessed on 17 Nov 2019.

Hao JQ, Hua WQ, Cha ZW, Li SK. Production technical progress and market analysis of adipic acid. Mod Chem Ind. 2012;32(8):1-4 (In Chinese).

Intergovernmental Panel on Climate Change. 2006 IPCC guidelines for national greenhouse gas inventories[M]. Intergovernmental Panel on Climate Change, 2006.

Intergovernmental Panel on Climate Change. Good practice guidance and uncertainty management in national greenhouse gas inventories: IPCC national greenhouse gas inventories programme[M]. IPCC, 2000

Intergovernmental Panel on Climate Change (IPCC). Revised 1996 IPCC Guidelines for National Greenhouse Gas Inventories. https ://www.ipcc-nggip.iges.or.jp/public/gl/invs1.html. Accessed on 17 November 2019.

Intergovernmental Panel on Climate Change (IPCC). The IPCC Second Assessment Report (AR2). https://www.ipcc.ch/report/ar2/syr/. Accessed on 17 November 2019.

Jiang Y, Xu YK, Ai XX. A review of nitrous oxide emission abatement technologies in adipic acid production. New Mater New Technol. 2018;44(9):56-7 (In Chinese).

Jinzhi Innovation Company. In China, adipic acid supply exceeds demand and capacity will be further expanded. http://www.sohu. com/a/339228421_100299669. Accessed on 17 November 2019. (In Chinese).

Kang L. The green route to adipic acid production. Chem Eng Oil Gas. 1999;1999(02):118 (In Chinese).

Lee SJ, Ryu IS, Kim BM, Moon SH. A review of the current application of $\mathrm{N}_{2} \mathrm{O}$ emission abatement in CDM projects. Int $\mathrm{J}$ Greenhouse Gas Control. 2011;2011(5):167-76. https://doi.org/10.1016/j.ijggc .2010.07.001.

$\mathrm{Lu} \mathrm{CH}$. The application of $\mathrm{N}_{2} \mathrm{O}$ catalytic technology in abatement adipic acid off-gas. Hebei Chem Eng. 2009;32(9):20-1 (In Chinese).

Ministry of the Environment, Japan. National Greenhouse Gas Inventory Report of JAPAN. http://www.cger.nies.go.jp/en/activities/ supporting/publications/report/index.html. Accessed on 17 Nov 2019.

NDRC China. Enhanced Actions On Climate ChaNGE: China's Intended Nationally Determined Contributions. https://www4. unfccc.int/sites/submissions/INDC/Published\%20Documents/ China/1/China's\%20INDC\%20-\%20on\%2030\%20June\%20201 5.pdf. Accessed on 17 November 2019.

NDRC China. National greenhouse gas inventory in 2005. Beijing: China Environmental Press; 2014.

NDRC China. The People's Republic of China Second Biennial Update Report on Climate Change. http://qhs.mee.gov.cn/kzwsqtpf/20190 
7/P020190701765971866571.pdf. Accessed 17 Nov 2019). (In Chinese).

NDRC China. The People's Republic of China Second National Communication on Climate Change. Available online: http://qhs. mee.gov.cn/kzwsqtpf/201904/P020190419524738708928.pdf. Accessed on 17 November 2019. (In Chinese).

NDRC China. The People's Republic of China Third National Communication on Climate Change. http://qhs.mee.gov.cn/kzwsq tpf/201907/P020190701762678052438.pdf. Accessed on 17 November 2019. (In Chinese).

NDRC China. The People's Republic of China First Biennial Update Report on Climate Change. http://qhs.mee.gov.cn/kzwsqtpf/20190 4/P020190419522735276116.pdf. Accessed on 17 November 2019.

Shi HX (2015) New technology for synthesis of adipic acid without producing $\mathrm{N}_{2} \mathrm{O}$ : energy conservation and emission abatement in petroleum and petrochemical industry. 2015;5(2):40 (In Chinese).

Shimizu A, Tanaka K, Fujimori M. Abatement technologies for $\mathrm{N}_{2} \mathrm{O}$ emissions in the adipic acid industry. Chemosp-Glob Change Sci. 2000;2000(2):425-34. https://doi.org/10.1016/S1465 -9972(00)00024-6.

Tong Q, Lu CY, Jiang DM. Difficulties and Suggestions in promoting the use of industrial low GHG technologies. China Econ Trade Guide. 2012;2012:47-8 (In Chinese).

Tong Q. Beware of the greenhouse gases emissions from adipic acid production. Sci Technol Rev. 2011;29(11):11 In Chinese.

Tong Q, Zhou S, Guo Y, Zhang Y, Wei X. Forecast and analysis on reducing China's $\mathrm{CO}_{2}$ emissions from lime industrial process. Int J Environ Res Public Health. 2019;16(3):500. https://doi. org/10.3390/ijerph16030500.

UK BEIS. UK Greenhouse Gas Inventory, 1990 to 2017. https:// unfccc.int/sites/default/files/resource/gbr-2019-nir-15apr19.zip. Accessed on 17 Nov 2019.
US EPA. Inventory of US greenhouse gas emissions and sinks. https:// www.epa.gov/ghgemissions/inventory-us-greenhouse-gas-emiss ions-and-sinks. Accessed on 17 November 2019.

Wen Y. China enters the second half of the late stage of industrialization. http://epaper.gmw.cn/gmrb/html/2017-06/16/nw.D1100 00gmrb_20170616_5-07.htm?div=-1. Accessed on 17 November 2019. (In Chinese).

Yan $\mathrm{H}$, Zhang YH, Tong HJ, Liu S. Strategy of $\mathrm{N}_{2} \mathrm{O}$ recovery from adipic acid plant exhaust. Energy Conserv Pet Petrochem Ind. 2018;8(1):41-3 (In Chinese).

Yang X, Wan H, Zhang Q, Zhou JC, Chen SY. A scenario analysis of oil and gas consumption in China to 2030 considering the peak $\mathrm{CO}_{2}$ emission constraint. Pet Sci. 2016;13(2):370-83. https://doi. org/10.1007/s12182-016-0089-2.

$\mathrm{Yu}$ Y. Advance in treatment technology of $\mathrm{N}_{2} \mathrm{O}$ in exhaust gas of adipic acid production. Industrial Catalysis. 2016;24(7):17-20 (In Chinese).

Zhang YL. Application of $\mathrm{N}_{2} \mathrm{O}$ emission abatement unit in adipic acid production. Petrochem Technol Appl. 2009;27(4):356-7 (In Chinese).

Zhang YL. Tentative ideas for recovering and use of $\mathrm{N}_{2} \mathrm{O}$ waste gas by new technologies. Chem Prod Technol. 2002;9(3):40-2 (In Chinese).

Zhao ZK. Phenol treatment of $\mathrm{N}_{2} \mathrm{O}$ tail gas from cyclohexane adipic acid production. Tianjin Chemical Industry. 2008;22(4):52-4 (In Chinese).

Zhu LJ, Li Y, Tang YY, Li YM, Zhang Q. The impacts of market reform on the market penetration of natural gas-fired electricity and renewable energy in China. Pet Sci. 2017;14(4):831-41. https ://doi.org/10.1007/s12182-017-0184-z.

Zhu Y. Technical analysis of $\mathrm{N}_{2} \mathrm{O}$ emission abatement in adipic acid production based on CDM projects. Sci Technol Vis. 2013;34:208-73. 